\title{
Sociedade e cultura futebolística: a visão e significância do futebol para o povo brasileiro como um elemento do pertencimento e autoestima
}

Football society and culture: the vision and significance of football to the Brazilian people as an element of the belonging and self-esteem

Sociedad y cultura futbolística: la visión y significación del fútbol para el pueblo brasileño como un elemento de pertenencia y autoestima

\author{
Vinícius Triches ${ }^{\mathrm{I}}$
}

\begin{abstract}
Resumo
Considerado o esporte mais popular do Brasil e do planeta, o futebol tem sido objeto de estudo cada vez mais frequente, tendo recebido relevante atenção de diferentes áreas. Com base em uma pesquisa exploratória e bibliográfica, buscou-se verificar as maneiras em que se deu a formação de uma sociedade e cultura futebolística no Brasil, percebendo a significação do esporte para o povo brasileiro. Notou-se que o futebol é um canal importante de vínculos emocionais entre os brasileiros, sendo que a sua prática ou o apoio a uma causa que o envolva é um elemento sempre importante em nossa sociedade.
\end{abstract}

Palavras-chave: Futebol; Controle Social; Cultura; Brasil

\begin{abstract}
Considered the most popular sport in Brazil and the planet, football has been the object of an increasingly frequent study, having received relevant attention from different areas. Based on an exploratory and bibliographical research, it was sought to verify the ways in which the formation of a soccer society and culture in Brazil was realized, comprehending the significance of the sport for the Brazilian people. It was noted that football is an important channel of emotional ties among Brazilians, and their practice or support for a cause that involves them is an important element in our society.
\end{abstract}

Keywords: Football; Social Control; Culture; Brazil

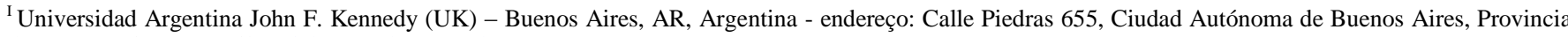
de Buenos Aires.- e-mail: vtriches@yahoo.com.br
} 


\section{Resumen}

Considerado el deporte más popular de Brasil y del planeta, el fútbol ha sido objeto de estudio cada vez más frecuente, habiendo recibido relevante atención de diferentes áreas. Con base en una investigación exploratoria y bibliográfica, se buscó verificar las maneras en que se dio la formación de una sociedad y cultura futbolística en Brasil, percibiendo la significación del deporte para el pueblo brasileño. Se notó que el fútbol es un canal importante de vínculos emocionales entre los brasileños, siendo que su práctica o el apoyo a una causa que lo rodea es un elemento siempre importante en nuestra sociedad.

Palabras clave: Fútbol; Control Social; Cultura; Brasil

\section{Introdução}

Considerado o esporte mais popular do Brasil e do planeta, o futebol tem sido objeto de estudo cada vez mais frequente no ambiente acadêmico. Sendo assim, tem recebido relevante atenção de diferentes áreas do conhecimento humano.

Dentro dessa perspectiva, é importante perceber de que forma se deu a apropriação do desporto na sociedade independente de classe social, tendo este recebido a alcunha no Brasil de "paixão nacional". Foi dentro dessa lógica que adentrou nos lares, escolas, bares e diferentes cantos do país, que cada vez mais foi se interessando tanto pela prática como pela discussão dos assuntos relacionados ao futebol.

Com base nessa realidade, o presente estudo teve como seu principal objetivoperceber as maneiras em que se deu a formação de uma sociedade e cultura futebolística no Brasil, com base na significação do esporte para o povo brasileiro em elementos como a autoestima e o pertencimento.

Na busca desse objetivo, realizou-se pesquisa exploratória, de acordo com o alcance de desenho, e pesquisa bibliográfica, no que se refere aos procedimentos técnicos. Gil (2014) assevera que uma pesquisa bibliográfica é aquela que é desenvolvida a partir de material já elaborado, sendo principalmente os artigos científicos e os livros.

O presente estudo divide-se em quatro partes. A segunda faz uma breve retomada histórica da chegada do futebol no Brasil, destacando os seus momentos iniciais até as questões atuais com base em elementos como torcidas, clubes e títulos. Já a terceira parte tem como foco a busca de um entendimento sobre os aspectos que foram vitais ao longo da história para a formação de uma sociedade e cultura do futebol no país, característica essa há muito tempo indissociável do próprio Brasil. Por fim, a quarta e última parte destaca as conclusões principais. 


\section{Futebol em território tupiniquim: da chegada ao esplendor do "futebol-arte" como sinônimo de brasilidade}

A mais tradicional explicação para a chegada do futebol ao Brasil, bem como a de sua socialização como prática esportiva no período posterior, é aquela que relaciona tais fatos a figura de Charles William Miller, filho do engenheiro ferroviário escocês John Miller e de Carlota Alexandrina Cox.

Essa explicação é quase uma unanimidade entre o grande público e entre os pesquisadores, de acordo com Melo (2000). O autor também destaca que Miller foi o introdutor do futebol no Brasil porque no ano de 1894, ao trazer duas bolas de futebol ao regressar da Inglaterra, acabou por organizar os primeiros jogos entre os sócios do São Paulo Athletic Club.

Entretanto, uma rápida pesquisa histórica mostra que alguns antecedentes foram também importantes para a posterior difusão do esporte ocorrida pela ação de Charles Miller no final do século XIX. Também deve ser mencionado que, assim como no restante no mundo, o país antes mesmo de seu descobrimento havia experimentado formas rudimentares de futebol, com a prática, por parte dos povos indígenas, de jogos similares, conforme destacado por Nogueira (1995).

O papel desempenhado por Miller é fundamental porque este, de acordo com Melo (2000), teve uma atuação preponderante na organização e difusão do futebol entendido como um campo esportivo, isto é, composto por competições, clubes e entidades que fazem a sua direção.

O que deve ser considerado é o fato de que, no período anterior a chegada de Charles Miller, conforme já comentado, o esporte já era praticado em terras brasileiras em diferentes locais, conforme variados relatos, com a adoção das normas que haviam sido elaboradas na Inglaterra. Mas como o futebol havia adentrado ao Brasil? O esporte havia chegado basicamente por dois canais fundamentais: através das escolas ou por meio de funcionários ingleses que moravam no país e trabalhavam em empresas de seu país de origem.

Melo (2000) afirma que os colégios jesuítas foram os responsáveis pela prática do esporte no país porque a Igreja Católica passou a adotar uma nova postura no final do século XIX na Europa em relação a este desporto.

Dentre os principais colégios jesuítas que começaram a adotar o futebol como prática pedagógica, se destacam o Colégio São Luiz, em Itu (SP), e o Colégio Anchieta, em Nova Friburgo (RJ). No primeiro, o futebol começou a ser praticado ainda em 1880, sendo que quando as bolas vindas da Europa acabavam 
furando, eram substituídas por bexigas de boi; já no segundo, os exercícios físicos, entre eles o futebol, foram introduzidos logo após a fundação da escola, ocorrida no ano de 1886.

A segunda via de entrada do futebol no país foi então por meio de funcionários ingleses que estavam morando no Brasil para trabalhar em empresas de seu país de origem. Nesse sentido, destacam-se organizações do ramo ferroviário, entre elas a São Paulo Railway e a Leopoldina Railway, bem como companhias de navegação e bancos, dentre outras. Carvalho e Marchi (2006) destacam que os funcionários das empresas ferroviárias citadas teriam aprendido a praticar o esporte, bem como jogado entre si nos períodos de folga do trabalho, ainda no ano de 1882, portanto, 12 (doze) anos antes de Charles Miller regressar ao Brasil.

Para Rossi e Mendes Jr. (2014), uma terceira via da entrada do futebol no país, não considerada por Carvalho e Marchi (2006), foi a prática do esporte por marinheiros no litoral brasileiro. Os autores afirmam que os ingleses, franceses e holandeses, sempre a bordo de navios mercantes ou de guerra, aproveitavam uma escala ou a chegada a um destino definitivo para "bater uma bolinha" desde meados do século XIX. Tal fato teria acontecido pela primeira vez em 1874, no pedaço de areia, em frente, onde hoje se localiza o Hotel Glória, no Rio de Janeiro, segundo Rossi e Mendes Jr. (2014).

O paulista do bairro do Brás Charles Miller irá desempenhar então papel fundamental na difusão do futebol no Brasil. Filho de um inglês que havia vindo trabalhar na São Paulo Railway, Miller havia ido a Inglaterra para estudar, ao mesmo tempo em que acabou se envolvendo profundamente com a prática do futebol em sua escola, a Banister Court School, em Southampton, inclusive até defendendo clubes locais, de acordo com Melo (2000). Ao retornar ao Brasil, trouxe consigo um conjunto completo para a prática esportiva daquela que se tornaria uma paixão nacional: duas bolas, as regras do jogo, chuteiras, camisas de equipe e as bombas para encher as bolas.

Dada a sua experiência e vontade de continuar praticando o esporte, este logo se torna membro do São Paulo Athletic Club, mas logo percebe que o futebol não é praticado nesse clube. No ano de 1895 , acaba por convencer os demais sócios a praticarem mais efetivamente o futebol, nesse momento são realizadas as primeiras partidas do esporte no Brasil. Rossi e Mendes Jr. (2014) destacam assim que a Inglaterra dará ao Brasil não somente o primeiro jogador, mas também o primeiro dirigente esportivo.

Dienstmann e Denardin (1999) destacam que esse primeiro jogo, realizado num capinzal da Várzea do Carmo, teve jogadores que usaram calças compridas. Também, os participantes tiveram, como primeiro ato para a realização da partida, de enxotar o gado que estava pastando no local. 
Murad (2012) irá destacar que em seus primeiros momentos o futebol era considerado um esporte da elite, somente praticado para a busca do lazer por parte das camadas sociais mais elevadas. Com caráter amador, era "[...] disputado pelos filhos das famílias ricas, todos brancos, cultos, elegantes e com duplo sobrenome" (MURAD, 2012, p. 75). Entretanto, dada a sua forma de divertir-se de maneira barata, simples para entendê-la e fácil de jogar, logo começa a chamar a atenção de uma parcela da população de origem e situação social excluída, pobre, mestiça e analfabeta.

O processo de popularização e democratização do esporte daquele que será considerado em tempos posteriores a maior manifestação da cultural brasileira se dará inicialmente, então, nas ruas (entre as décadas de 1910 e 1920).Depois será através dos clubes (a partir da década de 1920) e logo a seguir abrangerá aos mais variados espaços com o seu crescimento e profissionalização, a partir do ano de 1933.

O primeiro clube de futebol brasileiro foi fundado no dia 19 de julho de 1900 na cidade gaúcha de Rio Grande, tendo recebido o nome de Sport Club Rio Grande, de acordo com Beloni (2015). Fundado pelo alemão Johannes Minnemann, o clube tinha 21 (vinte e um) atletas, todos de origem europeia. Posteriormente, a data de 19 de julho acabou por ser oficializada como o dia do futebol brasileiro.

Nos quatro anos seguintes, inúmeros clubes acabaram por serem criados focados exclusivamente no futebol, muitos desses com grande tradição no futebol brasileiro até os dias atuais. São eles o Fluminense Football Club (fundado em 1902), o Grêmio Foot-Ball Porto Alegrense (fundado em 1903) e o Bangu Atlético Clube (datado de abril de 1904).

Cabe destacar que também é dessa época a fundação de diversos clubes representativos até os dias atuais, mas que vieram a adotar a prática futebolística somente nas décadas posteriores, o que acaba gerando dúvidas relativas ao seu pioneirismo no esporte. Exemplos são o Clube de Regatas do Flamengo (criado em 1895) e o Clube de Regatas Vasco da Gama (1898), ambos do Estado do Rio de Janeiro. O foco dos clubes na época de sua fundação esportiva era a prática do remo como atividade principal.

Retomando a questão dos períodos passados pelo futebol brasileiro no que se refere as diferentes transformações e avanços, a fase ocorrida entre os anos de 1894 e 1932 também ficou conhecida como a época do amadorismo, mesmo que esse fosse considerado, em certos momentos, um "amadorismo de gaveta" ou "amadorismo marrom". Dado que já nas primeiras décadas do século XX existissem jogadores que recebiam para jogar, mesmo que isso não fosse explicitamente revelado, visto que a ideia de pagar dinheiro para jogar não era bem aceita socialmente, de acordo com Carvalho e Marchi (2006). 
É dessa mesma época também que, de acordo com os autores, em função do processo de popularização do esporte, a pressão das torcidas dos clubes fará com que as agremiações comecem a repensar a questão da inclusão de jogadores não pertencentes à elite.

No ano de 1923, a pressão atinge seu auge, momento em que o Vasco da Gama irá decidir, pela primeira vez na história do futebol brasileiro, pela colocação de negros e brancos analfabetos, essa decisão será coroada com a conquista do campeonato carioca daquele ano. Esta se torna uma versão tradicional do processo de inclusão no futebol brasileiro, embora outras formas de participação de negros e/ou pobres, também sejam observadas em outras regiões em períodos anteriores, de acordo com os autores.

Também é desse momento histórico a criação da Confederação Brasileira de Desportos (CBD), por sugestão do chanceler Lauro Müller, no ano de 1916, visando a organização do futebol no país, através de uma entidade máxima, bem como a sua representação no exterior.

Já a fase que se inicia a partir de 23 de janeiro de 1933, com a implantação oficial da profissionalização do futebol no Brasil, se caracterizou pela consolidação de um período extremamente rico da história social desse esporte. O primeiro jogo da era profissional no país foi entre São Paulo Futebol Clube e Santos Futebol Clube, realizado no dia 12 de março desse ano, com vitória dos primeiros por 5 a 1.

A fase final do "amadorismo marrom" e os primeiros anos do profissionalismo são responsáveis também pelo surgimento de dois atletas que tem papel fundamental para a consolidação dos mitos do imaginário popular referente ao futebol no Brasil: o próprio Friendereich e Leônidas da Silva. Os atletas, ao atingirem renome nacional, acabam por fomentar a discussão sobre a imagem dos jogadores de futebol, bem como a relação latente e permanente entre negros e brancos no futebol, de acordo com Florenzano (2012).

Posteriormente, a consolidação do futebol como a "mania nacional" dos brasileiros se dará de forma definitiva nos anos 1970, momento da conquista do tri campeonato de seleções pelo escrete brasileiro durante o mundial realizado no México. É nesse período que, de acordo com Carvalho e Marchi (2006), o futebol será expandido para todo o território brasileiro, o que acabou por aumentar os interesses políticos, econômicos e sociais pelo esporte.

Uma das consequências desse processo é a realização do primeiro Campeonato Brasileiro de Futebol, no ano de 1971, com a participação de clubes das regiões Sul, Sudeste e Nordeste na competição, o que assegurava uma dimensão mais nacional ao esporte. Para se ter uma ideia, o Torneio Roberto 
Gomes Pedrosa, seu antecessor, foi disputado entre 1951 e 1966 somente entre clubes do estado do Rio de Janeiro e São Paulo, abrindo vagas para os representantes de Minas Gerais, Rio Grande do Sul, Paraná e Bahia somente a partir de 1967, de acordo com os autores.

É também desse período a instituição da Lei no 6.354/76, que determinou os direitos para os jogadores profissionais, passando estes a terem férias, bem como determina o período de intervalo entre as partidas realizadas. Tal lei dará origem a Deliberação nº 09/76, conhecida como a "Lei do Passe", responsável pela regulamentação das transações de vendas dos jogadores, de acordo com Rodrigues (2007).

O Brasil tornou-se, nas últimas décadas, uma potência do futebol mundial, com a conquista de inúmeros títulos tanto pela Seleção nacional como por seus clubes. Já a Copa do Mundo acabou sendo realizada no país em duas oportunidades: em 1950, com o Uruguai levantando a taça, e em 2014, com o título sendo conquistado pela Alemanha.

A Seleção Brasileira torna-se campeã mundial nas Copas do Mundo de 1958, 1962, 1970, 1994 e 2002, sendo vice nos anos de 1950 e 1998. Quanto à Copa América, o Brasil tem 9 (nove) títulos conquistados, alcançados nos anos de 1919, 1922, 1949, 1989, 1997, 1999, 2004, 2007 e 2019.

Já os clubes brasileiros de futebol são extremamente competitivos nas competições internacionais, além de serem admirados mundialmente, tanto pelos títulos conquistados como pelos jogadores e equipes que marcaram a história do esporte. Estes foram responsáveis por 11 (dez) títulos mundiais de clubes, bem como dezoito conquistas da Taça Libertadores da América.

\section{Pertencimento e autoestima do povo brasileiro com base no esporte: a sociedade e a cultura do futebol no Brasil}

Esporte de caráter integrador dos mais diferentes grupos sociais, o futebol foi, ao longo da história, uma das formas de visualizar o pertencimento, no que se refere a um determinado vínculo emocional ou afetivo a um clube ou seleção nacional ou regional. E também a integração, com base no agrupamento de determinadas classes ou categorias populares, mediante a sua prática esportiva, bem como a uma determinada causa em que o mesmo esteja envolvido.

Um dos fatores que fez com que o futebol no Brasil fosse, desde os seus primórdios, um esporte que atraiu grandes multidões para a sua prática foi o fato deste ser demasiadamente barato e de simples entendimento, o que tornava fácil para ser jogado, tanto pelas classes mais abastadas, como pela 
expressiva parcela da população brasileira que era excluída, pobre, mestiça e analfabeta, de acordo com Murad (2012).

Sobre esse processo de inclusão das classes menos favorecidas e a consolidação de uma forma de jogar e entender futebol no Brasil a partir dessa perspectiva, o autor destaca que:

\begin{abstract}
A história social do futebol brasileiro é um capítulo de nossas lutas sociais, políticas e culturais. A popularização/democratização do futebol, fruto da resistência e das lutas das camadas desfavorecidas da sociedade, foi consolidada nas décadas de 1940 e 1950. Os setores pobres da população, antes impedidos de participar, foram se impondo e trazendo para o jogo um "jeito brasileiro", uma espécie de "estilo", uma "marca própria", por assim dizer. É uma herança de nossas identidades culturais indígenas, portuguesas e, sobretudo, negras. No "estilo" brasileiro de jogar, as raízes culturais de nossas classes oprimidas se fizeram presentes. (MURAD, 2012, p. 77).
\end{abstract}

Essa formação histórica fez com que, ao longo dos tempos, para o autor, o esporte tenha se tornado uma paixão verdadeiramente coletiva que acaba por mexer com praticamente todo o país, independente dos diferentes grupos, classes sociais, padrão de renda, escolaridade e região. Assim, acabou por se tornar um símbolo muito forte dos valores culturais nacionais, constituindo um modo de ser do brasileiro, o que o leva a ser entendido como uma identidade coletiva nacional.

Considerado tradicionalmente o esporte mais popular do Brasil, Melo (2000) destaca que em solo brasileiro o futebol é uma prática cultural tão significativa quanto o teatro, o cinema e as artes plásticas, dentre outras. Entretanto, nenhuma das manifestações citadas tem um poder de mobilizar tantas pessoas ao mesmo tempo como o futebol, visto que mexe amplamente com as paixões, desejos e sentimentos dos torcedores envolvidos.

Segundo Murad (2012), talvez uma das explicações para o futebol ser tão importante na vida dos brasileiros é o fato de ter sempre representado as diferentes contradições sociais e os dilemas do povo. Permitindo, assim, ser uma forma de entender a sociedade através de diferentes campos: a formação étnica, a miscigenação, a musicalidade e a cultura corporal, dentre outros.

Também aspectos da estrutura social perversa do Brasil podem ser vistos através do esporte, sendo eles a concentração de renda, do poder e de oportunidades. É dessa forma que, através da experiência do futebol, “[...] podemos 'ler' a sociedade brasileira no que ela tem de positivo e de negativo" (MURAD, 2012, p. 80).

O futebol seria, então, para o autor, uma grande forma de representar a sociedade do Brasil, constituindo um conjunto de retratos da vida nacional, em que esses aspectos são seguidamente revelados nos campos, nas torcidas, nas comemorações e nas organizações dos torneios. 
Todos esses locais e esferas mostram e nos lembram de diferentes paradoxos, ambiguidades e tensões culturais do Brasil. Ao mesmo tempo em que se percebe a alegria, a criatividade, a capacidade de organização independente, a possibilidade de luta, resistência, superação e democracia, o futebol também representa um componente nacional que está ancorado no autoritarismo dos dirigentes (políticos ou esportivos), o descaso das autoridades, a corrupção, a impunidade, a concentração de renda, a falta de oportunidades e a violência.

Carvalho e Marchi (2006) destacam que, na mesma linha que Murad (2012), o futebol no Brasil acabou por se tornar uma tendência instintiva, um resultado do povo e da sociedade. Para tanto, apresentam exemplos, como o fato de que uma ginga dentro de campo é equivalente ao "jeitinho brasileiro" de resolver/driblar os problemas do dia-a-dia e a onda de violência social, bem como a impunidade e o favorecimento de poucos, problemas típicos do cotidiano do brasileiro, é transferida repetidamente para o ambiente do futebol.

Dentro dessa perspectiva, o futebol é, para os autores, altamente influenciado pela sociedade, visto que é um veículo de permanência de valores sociais, ao mesmo tempo em que exerce influência na própria vida da sociedade brasileira, ao emanar seus valores, contradições e interesses no espectro variado de configurações sociais e culturais existentes.

Fácil também é perceber no Brasil os amplos e diferentes espaços que o esporte de origem inglesa ocupa na mídia tradicional (televisão, jornal e revistas, por exemplo) bem como nas consideradas modernas e alternativas (sítios eletrônicos, blogs e redes sociais) ao longo de uma rápida pesquisa.

Notícias que apresentam os principais resultados dos jogos do campeonato estadual, nacional ou continental, esses realizados na noite anterior, bem como as principais perspectivas para a próxima partida das equipes locais, regionais ou nacionais, no que se refere a formação tática e técnica e os reforços que serão agregados aos times no próximo jogo ou competição, recebem grande atenção e exposição por parte dos diferentes tipos de mídias comentados acima.

Esse processo de acompanhamento do futebol por parte da mídia teve início nas primeiras décadas do século XX, quando o esporte passa a ser um evento social que não é mais de interesse somente dos seus praticantes, mas também de uma massa expectadora e interessada pelo mesmo de forma permanente. Fatos como a vinda de equipes internacionais para o país, bem como as primeiras disputas interestaduais, entre o Rio de Janeiro e São Paulo, são eventos que colocam o esporte em evidência, de acordo com Melo (2000). 
Também é desse período a participação do país nas primeiras competições internacionais do esporte. Inicialmente coroadas com fracassos, os êxitos logo são alcançados, com a glória máxima sendo alcançada em 1958, ano da conquista do primeiro título mundial de seleções pelo Brasil em campeonato realizado na Suécia. As Copas do Mundo passam a ser acompanhadas pelos brasileiros com uma paixão nacionalista, muitas vezes cooptada pelo contexto político do momento, visto que "[...] não era mais um simples jogo desinteressado. Era o país que estava em jogo" (MELO, 2000, p. 23).

Sendo um objeto de interesse constante por boa parte do público nacional, bem como também um “filão" interessante a ser atendido pela mídia, o futebol e suas principais dimensões é uma prática no Brasil que passa de pai para filho, tanto no que se refere ao amor a um clube, como também no imaginário da representação de algum aspecto de nossa sociedade. Assim:

Quantas músicas retrataram o futebol; quantos filmes, peças de teatro e novelas tiveram o futebol como personagem principal ou como cenário para suas tramas; quantas horas diárias a imprensa televisiva e radiofônica gastam com o futebol; quanto espaço diário de jornal é dedicado a este esporte, em detrimento de outros; quantas emissoras de rádio transmitem o mesmo jogo, nas tardes de domingo. (DAOLIO, 2000, p. 33).

É dentro desse contexto que se pode verificar também que uma das formas de perceber a permanente popularidade do futebol está na extrema fidelidade dos torcedores aos seus clubes. De uma forma geral, percebe-se que independente da fase negativa do clube e o sofrimento e angústia que esses momentos tendem a representar, o torcedor acaba sempre por acreditar em dias melhores vindouros para a sua agremiação esportiva.

Daolio (2000) destaca que a fidelidade a um clube de futebol no Brasil vem desde o dia do nascimento, quando o garoto (ou garota) recebe um nome, uma religião e um clube de futebol para o qual deve ou deveria torcer a vida toda, processo esse que passa normalmente pelo pai. Vê-se, então, que o brasileiro aprende "[...] a torcer por uma determinada equipe de futebol, diferentemente das equipes de voleibol ou basquetebol que, como representantes de empresas, mudam de nome a cada temporada" (DAOLIO, 2000, p. 34-35).

O futebol pode ser visto então como um campo fértil para a percepção da identidade social, dado que a rivalidade clubística é calcada basicamente na diferença, de acordo com Morato (2005). No ato da escolha de um clube, está a aceitação e o reconhecimento do seu patrimônio, além da negação a tudo aquilo que é diferente.

Um clube pode ser visto como uma "tribo" diferente que vai manter suas crenças e tradições também diferentes, sempre "olhando" para todas as outras com desprezo e superioridade, dado que 
acredita que o "[...] seu time, a sua tribo, é melhor do que as outras em todos os aspectos" (MORATO, 2005, p. 93).

Também é interessante notar que no mundo dos esportes e, mais especificamente, do futebol, há uma extrema curiosidade por parte dos torcedores com o perfil de jogadores que acabaram por se tornarem ídolos, dado que foram coroados com grandes êxitos e conquistas pelos clubes e seleções.

Helal (2001a) destaca que normalmente "suas trajetórias de vida rumo à fama e ao estrelato costumam ser narradas na mídia de forma mítica, conferindo uma maior dramaticidade às conquistas" (HELAL, 2001a, p. 135). A observação histórica no Brasil das diferentes narrativas que resgatam a trajetória da vida dos ídolos de futebol enfatizam, principalmente, de acordo com o autor, aspectos como a genialidade e o improviso como os componentes fundamentais para o sucesso no esporte.

Entretanto, cabe nesse momento a seguinte indagação: porque um fenômeno de massas não é plenamente sustentável ao longo do tempo sem a presença permanente de "heróis", "estrelas" ou ídolos?

A resposta parece estar, conforme Helal (2001b), no fato de que esses agentes são uma "porta" que leva as pessoas a se identificarem com o evento esportivo em si, dado que os mesmos representam a "nossa comunidade" que frequentemente gosta de saudar e idolatrar situações em que o esportista acaba por sobrepujar obstáculos que são considerados aparentemente de caráter intransponível.

É dessa maneira que a missão a ser cumprida pelo "herói" é a de conceder dádivas aos seus semelhantes, visto que:

O herói parte do mundo cotidiano e se aventura numa região de prodígios sobrenaturais; ali encontra fabulosas forças e obtém uma vitória decisiva; o heróiretorna de sua misteriosa aventura com o poder de trazer benefícios aos seus semelhantes. (CAMPBELL, 1995, p. 36 apud HELAL, 2001b, p. 154).

A percepção é que o futebol permanece sendo, ainda de acordo com o autor, um terreno extremamente fértil para que essa característica do "ídolo-herói" possa se reproduzir no sentido da produção de mitos e ritos que são relevantes para a comunidade.

Como são dotados de talento e carisma, os ídolos denotam características que acabam por singularizá-los e diferenciá-los do restante da população, que os percebe como “ [...] paradigmas dos anseios sociais e através das narrativas de suas trajetórias de vida, uma cultura se expressa e se revela" (HELAL; MURAD, 1995 apud HELAL, 2001b, p. 154).

Damo (2014) vai destacar que, retomando o papel da identidade vinculada ao futebol e seu entendimento como esporte de diferenciados vínculos sociais e culturais, essa relação se dá devido à necessidade de compreender o processo clássico, mas sempre renovado, de qualquer dinâmica de grupo. 
O campo do futebol é, fundamentalmente, voltado ao espetáculo, uma fonte generosa de questões a serem investigadas, na mesma perspectiva de Murad (2012). Assim, ali se apresentariam “[ [...] extensos e multifacetados os arranjos em termos de identidades e alteridades" (DAMO, 2014, p. 26).

O futebol vai representar, por sua estrutura, uma disputa bem demarcada entre um eu (ou nós) e um outro (ou outros), o que vai acabar favorecendo a instauração de aspectos como a identidade e a diferenciação. Esse processo é perceptível porque, de acordo com o autor, toda a partida de futebol é “[...] um rito do tipo disjuntivo, no qual os contendores, partindo de uma situação de pretensa igualdade, lutam para promover uma cisão entre vencedores e vencidos" (DAMO, 2014, p. 26).

Dessa forma, destaca que dois grandes sistemas de representação estão solidamente constituídos no futebol enquanto espetáculo. O primeiro sistema é relacionado aos clubes, denominado de clubismo, e o segundo direcionado às seleções nacionais, visto como patriotismo ou nacionalismo, dada a ausência de termos mais apropriados. De acordo com essa perspectiva:

Nesse futebol, um time jamais entra em campo apenas pensando nos interesses, expectativas e fragilidades de seus integrantes. Ele é preparado para algo mais importante, digamos, que é representar as aspirações de uma comunidade de sentimento, que pode ser um clube ou uma nação/pátria. (DAMO, 2014, p. 27).

Essa maneira de perceber o futebol e o trato de um jogo e seu amplo contexto é facilmente vista, conforme já discutido por Melo (2000), na visão de que a Seleção Brasileira é a seleção de todos os brasileiros, e o "torcer" é representado como sinônimo de brasilidade e amor ao país, o que muitas vezes leva ao questionamento de que o povo brasileiro se identifica mais com as questões nacionais associadas ao futebol do que com a política, por exemplo.

\section{Conclusão}

Esporte praticado e cultuado no Brasil há cerca de 12 (doze) décadas, responsável por êxitos históricos importantes em competições internacionais por parte dos clubes e Seleção Brasileira, o futebol é um canal importante de vínculos emocionais entre os brasileiros de diferentes formas. Sendo assim, percebe-se que a sua prática ou o apoio a uma causa que o envolva é um elemento sempre importante na nossa sociedade.

A popularização do esporte deu-se basicamente com a inclusão da população mais pobre em sua prática desde os primeiros momentos, o que fez com que fosse criado o tal "jeito brasileiro" de jogar 
futebol. Isso, serviu de fomento a consolidação do desporto como uma paixão nacional que incluía todas as classes sociais.

Enquanto transmissor inconteste de uma manifestação cultural relevante, o futebol acabou ao longo do tempo sendo elemento de mobilização das pessoas com base em um maior entendimento do próprio Brasil. Principalmente quando se observa as suas principais realidades, problemas e contradições, muitas dessas históricas e que recorrentemente são retomadas.

Também, é evidente perceber que tal manifestação somente pode ser espraiada territorialmente por causa do relevante espaço ocupado pelo esporte ao longo das décadas na mídia tradicional, mas também mais recentemente nas mídias alternativas. Uma vez que as últimas sempre foram canal relevante para o acompanhamento dos jogos e dos debates que os campeonatos acabavam por suscitar.

Paixão que normalmente passa de pai para filho, o gosto pelo futebol no Brasil e a sua imensa popularidade deu-se também com base na fidelidade dos torcedores aos seus "clubes do coração", que, uma vez escolhidos, acabam por representar uma identidade social permanente, em que a diferenciação entre o "nós" (nosso clube) e o "eles" (clube rival) será a característica principal da rivalidade eterna. Dentro desse pertencimento clubístico, também merecerá destaque o papel dos ídolos dos clubes, que sempre serão a referência das vitórias alcançadas e da valorização dos símbolos do clube escolhido.

\section{Referências}

BELONI, P. Dia do Futebol no Brasil: conheça as origens do esporte masculino e feminino. Batanga. Disponível em: <http://www.batanga.com.br/1042/dia-do-futebol-no-brasil-conheca-as-origens-do-esportemasculino-e-feminino>. Acesso em: 03 dez. 2017.

CARVALHO, A. I.; MARCHI, F. L. de. Futebol: história e bastidores de uma paixão nacional. Goiânia: Vieira, 2006.

DAMO, A. S. O espetáculo das identidades e alteridades: as lutas pelo reconhecimento no espectro do clubismo brasileiro. In: CAMPOS, F. de; ALFONSI, D. (org.). Futebol objeto das ciências humanas. São Paulo: Leya, 2014.

DAOLIO, J. As contradições do futebol brasileiro. In: CARRANO, P. C. R. (org.). Futebol: paixão e política. Rio de Janeiro: DP\&A, 2000.

DIENSTMANN, C.; DENARDIN, P. E. Um século de futebol no Brasil: do Sport Club Rio Grande ao Clube dos Treze. Porto Alegre: APLUB, 1999.

FLORENZANO, J. P. Futebol e Racismo: o mito da democracia racial em campo. Futebol \& Cultura. Sociedade. São Paulo: Goethe - Institut São Paulo. 2012. Disponível em: <www.goethe.de/ins/br/sap/prj/fus/ges/pt9657066.htm> Acesso em 15 nov. 2017. 
GIL, A. C. Métodos e técnicas de pesquisa social. 6. ed. São Paulo: Atlas, 2014.

HELAL, R. As idealizações de sucesso no imaginário brasileiro: um estudo de caso. In: HELAL, R.; SOARES, A. J.; LOVISOLO, H. A invenção do país do futebol: mídia, raça e idolatria. Rio de Janeiro: Mauad, 2001a.

Mídia, construção da derrota e o mito do herói. In: HELAL, R.; SOARES, A. J.;

LOVISOLO, H. A invenção do país do futebol: mídia, raça e idolatria. Rio de Janeiro: Mauad, 2001b.

MELO, V. A. de. Futebol: que história é essa?! In: CARRANO, P. C. R. (org.). Futebol: paixão e política. Rio de Janeiro: DP\&A, 2000.

MORATO, M. P. A dinâmica da rivalidade entre pontepretanos e bugrinos. In: DAOLIO, J. (org.). Futebol, cultura e sociedade. Campinas, SP: Autores Associados, 2005.

MURAD, M. A violência no futebol. São Paulo: Saraiva, 2012. (Coleção para entender).

NOGUEIRA, C. J. G. Educação Física na sala de aula. Sprint: Rio de Janeiro, 1995.

RODRIGUES, F. X. F. O fim do passe e a modernização conservadora no futebol brasileiro (20012006). Tese (Doutorado em Sociologia). Instituto de Filosofia e Ciências Humanas, Universidade Federal do Rio Grande do Sul, Porto Alegre, 2007.

ROSSI, J.; MENDES Jr., L. Guia politicamente incorreto do futebol. São Paulo: LeYA, 2014.

\section{Como citar este artigo}

TRICHES. V. Sociedade e cultura futebolística: a visão e significância do futebol para o povo brasileiro como um elemento do pertencimento e autoestima. Revista Kinesis, Santa Maria, v. 38, p.01-14, 2020.

* O presente trabalho não contou com apoio financeiro de nenhuma natureza para sua realização. 